PROGRAMAS DE TRANSFERENCIA DE RENTA CONDICIONADA Y POBLACIÓN INMIGRANTE EN ARGENTINA: la restringida accesibilidad a la Asignación Universal por Hijo y al Programa de Respaldo a Estudiantes de Argentina, en el marco del modelo de Desarrollo con Inclusión

\title{
Verónica de Avila
}

Universidad Nacional del Centro de la Provincia de Buenos Aires (UNICEN)/Universidade Federal do Maranhão (UFMA)

PROGRAMAS DE TRANSFERENCIA DE RENTA CONDICIONADA Y POBLACIÓN INMIGRANTE EN ARGENTINA: Ia restringida accesibilidad a la Asignación Universal por Hijo y al Programa de Respaldo a Estudiantes de Argentina, en el marco del modelo de Desarrollo con Inclusión

Resúmen: Contemplando que los Programas de Transferencia de Renta Condicionada (PTRC) adquirieron relevancia en el siglo XXI en América Latina y el Caribe, a partir de un análisis bibliográfico y documental, el artículo problematiza la accesibilidad restringida de la población inmigrante a la Asignación Universal por Hijo y al Programa de Respaldo a Estudiantes de Argentina, de los PTRC de gran envergadura enmarcados en el Modelo de Desarrollo con Inclusión Social vigente desde el año 2003 en Argentina.

Palabras-clave: Estado, derechos sociales, políticas sociales.

CONDICIONAL CASH TRANSFER PROGRAMS AND MIGRANT POPULATION IN ARGENTINA: restricted acces to the Universal Child Assignment and Programme of Suport for Students from Argentina, under the model of Development with Inclusion

Abstract: Considering that the conditioned income transfer programs(PTRC in portuguese) acquired relevance in the twenty-first century in Latin America and in Caribbean, from a bibliographic and documentary analysis, the article questions the restricted accessibility of the immigrant population to the Universal contribution per Son and the Support Program for Students in Argentina, of the PTRC's major framed in the current development model with social inclusion since 2003 in Argentina.

Key words: State, social rights, social policies. 


\section{INTRODUCCiÓN}

Se parte de comprender que es en el contexto de las contradicciones de la sociedad capitalista, que reside en la producción colectiva de la riqueza y su apropiación privada, que la Política Social suge, en el marco del Estado Moderno ${ }^{1}$, como proceso de institucionalización estatal dirigido a dar respuestas a las expresiones de la cuestión social ${ }^{2}$, participa en procesos redistributivos expresados en bienes y servicios sociales, construyendose formas particulares de incorporación a la esfera pública estatal de las demandas sociales de la clase trabajadora, en un marco de tensiones y luchas, bajo procesos de selectividad estructural y fragmentación, que opera en términos históricos como un factor de dispersión y control, con mayor o menor intensidad según las relaciones de poder resultantes (SOTO, 2005). En el caso Argentino, como en otros países marginales en la distribución del poder económico a nivel internacional, las políticas que se desarrollan están signadas por lineamientos efectuados por organismos internacionales de crédito, a partir de las inmensas deudas adquiridas con los mismos en momentos de crisis.

En el presente artículo se abordan los Programas de Transferencia de Renta Condicionada (PTRC) existentes en Argentina desde el año 2003, momento de inflexión en la configuración del Sistema de Protección Social vigente, analizando particularmente la Asignación Universal por Hijo (AUH) y el Programa de Respaldo a Estudiantes de Argentina (PROGRESAR), en ejecución, dada la gran envergadura que adquieren en el Modelo de Desarrollo con Inclusión Social desarrollado por el Gobierno vigente. Se problematizará la cuestión de las posibilidades y dificultades para la accesibilidad de la población inmigrante que habita en el territorio argentino a los mismos, cuestión escasamente tratada hasta el momento en el ámbito académico, contemplando las características que adquiere esta población en la composición demográfica argentina actual; y que, a partir del año 2004 adquiere vigencia la Ley de Migraciones, Ley n. 25.871, de 17 de diciembre de 2003, asumiéndose un enfoque más aperturista y regionalista que el anterior, fundamentado en los Derechos Humanos, que pretendería garantizar la integración (inclusión?) de esta población a nuestro país. En este sentido se intenta contribuir a la reflexión y al análisis sobre la recepción que se brinda a los inmigrantes en materia de políticas públicas de asistencia, contemplándolas como posibilidad de garantía de los Derechos Sociales (y Humanos).

\section{EL SURGIMIENTO DE LOS PTRC EN LA CONFIGURACIÓN ACTUAL DEL SISTEMA CAPITALISTA}

En el actual contexto internacional, definido por D. Harvey (2004) como de acumulación flexible, en el cual se reconfiguran tanto las relaciones sociales fundamentales como las instituciones, la flexibilidad y precariedad se constituyen en la estrategia hegemónica que afecta mayormente a la clase trabajadora de los países menos desarrollados. En este sentido, si observamos el panorama de la Región, luego de la implementación de las políticas neoliberales de la década de 1990 se acentuó la desigualdad y la brecha existente entre pobres y ricos, donde los primeros son los mayoritarios. ${ }^{3}$ Esa década se caracterizó por la poca efectividad o ausencia de políticas de inclusión/participación de los sectores trabajadores en la actividad económica de producción, acumulación y distribución de la riqueza. Se destacaron las políticas desarrolladas en base a lineamientos del Consenso de Washington ${ }^{4}$, promoviéndose,

[...] la culminación de la forma de organización social centrada en el capital industrial y su reemplazo por la forma que despliega el capital financiero. (SOTO; TRIPIANA, 2014, p. 275).

Respecto a la situación actual, Silva (2014, p. 62) plantea que:

A primeira década do século $X X I$ mostra na América Latina-con suas heterogeneidades e complexidadesalgumas inflexões em relacão às décadas finais do século $X X$, quando predominou claramente a prática neoliberal. Em um contexto de crescimento econômico se observam melhorias em alguns indicadores sociais, centralmente na pobreza, na indigência e na desocupação. Ao mesmo tempo, observam-se criticas às orientacões das reformas neoliberais. Todavia, apesar de estas melhorias, permanecem enormes dívidas estruturais em materia de igualdade e de bem-estar universal. É nesse contexto que adquierem centralidade formas de proteção social não contributivas, centralmente os denominados programas de transferencia de renda condicionada (PTRC), os quais estão presentes atualmente em muitos países da região.

Los PTRC, definidos desde una perspectiva de capital humano ${ }^{5} \mathrm{y}$, en este sentido, basados en una "[...] concepción individualista de la sociedad." (SOTO, 2013, p. 79), están dirigidos a romper el ciclo de transmisión intergeneracional de la pobreza, y han tenido una gran repercusión. ${ }^{6} \mathrm{Su}$ estructura básica consiste en la entrega de recursos monetarios ${ }^{7}$ y no monetariosa a familias en situación de pobreza, que tienen hijos menores de edad, con la condición de que estas cumplan con ciertos compromisos asociados al mejoramiento de sus 
capacidades humanas (CECCHINI; MADARIAGA, 2011), destacándose las indicaciones en relación a salud y educación.

Los procesos antes mencionados, adquirieron su particularidad en cada país. En en caso de Argentina, el año 2001 fue el momento en el que se visibilizó la crisis del modelo neoliberal impuesto en la década anterior ${ }^{8}$, manifestándose en un colapso económico, social y político-institucional, producido por una importante devaluación de la moneda, el aumento del desempleo, la permanencia de la informalidad laboral, la caída de los salarios y el incremento significativo en los índices de pobreza e indigencia. ${ }^{9}$ En el año 2002, la Argentina alcanzó el mayor pico de pobreza de la historia reciente llegando al 21,5\% (INSTITUTO NACIONAL DE ESTADÍASTICAS Y CENSOS, [2002]).

Fue recién en el año 2003 cuando se inicia un período de disminución de la pobreza y la indigencia; disminución de la desocupación y aumento de la tasa de empleo. Lo que no implició una mayor distribución de la riqueza.

Así emerge la categoría de 'trabajador pobre' (el obrero que aún trabajando no cubre la canasta familiar -alimentaria o total-), frente a la figura del 'desocupado pobre' que prevalecía en la crisis del 2001. Tener trabajo no garantiza cubrir las condiciones materiales de existencia [...] (SOTO; TRIPIANA, 2014, p. 278, grifos dos autores).

Ante esta compleja situación, en el marco de manifestaciones, y de lucha de clases, comienza a vislumbrarse a partir del año 2003 , con la asunción de Néstor Kirchner a la presidencia de la Nación y de su hermana, Alicia Kirchner, como ministra de Desarrollo Social la necesaria recomposición material del consenso (SOTO, 2013). Se inició allí un proceso de cambios en la política social asistencial.

Se cuestiona desde la perspectiva oficial, la lógica de focalización, la perspectiva asistencialista divorciada de la garantía de derechos y la extensa fragmentación de las políticas sociales. La política social se organiza bajo tres ejes de acción (alimentario, transferencias monetarias condicionadas y economía social), intentando unificar la pluralidad de programas existentes con anterioridad. (SOTO, 2013, p. 71).

El Estado argentino vuelve a asumir, entonces, a inicios del siglo XXI, su rol interventor, aumentando el gasto social y desplegando el sistema de Seguridad Social, con un fuerte discurso basado en la inclusión y los Derechos Sociales. En este sentido, crea programas no contributivos de asistencia social con una amplia cobertura, entre los que se destacan
Ios PTRC, emergiendo desde entonces el Programa jefas y jefes de Hogar desocupados (PJDD) en el período 2002-2005'10; el Programa Familias con inclusión social (desde 2006) ${ }^{11}$, resultando de gran envergadura la implementación de la AUH a partir del año 2009, que absorvió a los beneficiarios de los programas mencionados anteriormente, resultando esto un incremento en el monto de dinero transferido a las familias y, por tanto, un avance en la garantía de derechos sociales. Según datos aportados por la CEPAL, en el año 2010 la cobertura de los PTRC en Argentina era del 8,3\%, abarcando al $100 \%$ de la población indigente y al $46,4 \%$ de la población considerada pobre (CECCHINI; MADARIAGA, 2011).

Finalmente, a inicios del año 2014 el Poder Ejecutivo Nacional coloca en funcionamiento el PROGRESAR, destinado a jóvenes, generándose con su implemantación criterios de legitimación, ahora también, desde la perspectiva de los derechos de la juventud.

La AHU y el PROGRESAR se encuentran vigentes actualmente, resultando de gran envergadura por su masividad ${ }^{12}$ y las características que adquieren, razón por la cual fueron seleccionados para el presente trabajo. Los mismos serán analizados en el apartado número 3. A continuación, interesa poner en relieve las características de la población inmigrante en la actual composición demográfica argentina, comprendiendo su incidencia; y la Politica Migratoria que fue pensada para esta población, e implementada por el Estado Argentino en este último período histórico, en el marco del Modelo de Desarrollo con Inclusión desplegado por el Gobierno kirchnerista ${ }^{13}$, presidido actualmente, desde el mes de Diciembre del año 2007, por Cristina Fernández de Kirchner.

\section{LA POBLACIÓN INMIGRANTE $Y$ LAS MUDANZAS EN LA POLÍTICA MIGRATORIA ARGENTINA}

La inmigración constituyó históricamente un componente muy significativo en la dinámica demográfica argentina así como en la vida social, económica y cultural de nuestro país. ${ }^{14}$ Fue a mediados del siglo $\mathrm{XX}$ cuando disminuyó el flujo de inmigración ${ }^{15}$ al tiempo que comenzó a cambiar su composición, aumentando la migración intraregional.

Estos inmigrantes -ahora denominados regionales (Jelín y Grimson, 2006) desde la incorporación de los de nacionalidad peruana- se han ido insertando en diferentes espacios del mercado de trabajo argentino, desempeñando un papel complementario o adicional a la mano de obra nativa. Su participación actual en nichos específicos (servicio doméstico, construcción, comercio, 
industria manufacturera, entre otros) refuerza la idea de una inserción segmentada en los mercados de trabajo (OIM, 2008), resultando, a su vez, una inserción desventajosa en relación a la de los nativos, y de alta precariedad, fundamentalmente para los indocumentados. (NICOLAO, 2011, p. 111).

La probabilidad de que los trabajadores inmigrantes se encuentren ocupados bajo condiciones precarias es significativamente más alta que la del conjunto de los trabajadores (Asamblea Permanente por los DDHH, 2010), el trabajo informal o denominado en negro abunda entre los migrantes cualquiera sea su nacionalidad (GÓMEZ PIANA, 2014). En este sentido, son funcionales al desarrollo económico-productivo del país, pagando los costos del mismo.

¿Quienes son estos sujetos? Si observamoslos resultados del último Censo Nacional de Población, Hogares y Viviendas realizado en la Argentina, para el año 2010 la población extranjera era de 1.805.957 personas, representando el $4,5 \%$ respecto del total de la población censada. De estos últimos, 1.402.568 provienen de países limítrofes más Perú; siendo la población paraguaya la mayoritaria, seguida por la boliviana, la chilena, la peruana y la uruguaya (en ese orden). En tanto que 299.394 nacieron en Europa, 31.001 en Asia, 2.738 en Africa y 1.425 en Oceanía. La población China y del resto de Asia presenta la menor afluencia. Se visualiza, asimismo, una concentración territorial de los mismo en la provincia de Buenos Aires (52,2\%) y en la Ciudad Autónoma de Buenos Aires (CABA) $(21,1 \%)$.

Los inmigrantes de origen americano al igual que los de África y Asia, presentan una importante proporción de población en edades activas (15-64 años). $Y$ se visualiza, sobre todo en inmigrantes americanos, el predominio de la inmigracion femenina. En cuanto al nivel de instrucción de la población inmigrante, los limítrofes cuentan con niveles educativos en promedio inferiores a los de la población total de la Argentina, mientras que los inmigrantes regionales no limítrofes, los inmigrantes del continente europeo y el resto de los inmigrantes poseen perfiles educativos más elevados que los del promedio (ORGANIZACIÓN INTERNACIONAL PARA LAS MIGRACIONES, 2012).

¿Por qué deciden migrar? Entre los factores de la migración internacional, Solimano (2003), destaca a la expectativa de obtener en el extranjero mejores ingresos que en el país de origen; la existencia de redes sociales de apoyo a los migrantes, las políticas migratórias y los costos de migrar, los conflictos bélicos, la discriminación étnica y la persecución política en el país de origen. Por su parte, Nicolao (2010) expone que, para los inmigrantes regionales, los factores serían la demanda de mano de obra en Argentina, primero en las actividades agrícolas en las provincias fronterizas con los países emisores, y luego en las grandes ciudades en los sectores de la industria y los servicios; situaciones expulsoras en algunos de los países emisores, como periodos de autoritarismo político y crisis económicas; la proximidad geográfica; la permeabilidad de las fronteras argentinas; la proximidad cultural y el idioma común, etc.

Como se observa tanto la situación económica como laboral constituyen dos importantes factores para el arribo de ciudadanos de otros países hacia Argentina. Insertandose estos sujetos, mayormente, en empleos con baja o nula calificación; y en condiciones de trabajo sin protección social o con protección mínima puestos de trabajo, obteniendo bajas remuneraciones. Puede asumirse, entoces, que sus ingresos son mínimos. ${ }^{16}$ Lo que, los convierte en potenciales usuarios de los PTRC.

\subsection{Avances en matéria de Política Migratoria}

En el marco de reformas implementadas, una mudanza de gran relevancia en este último período histórico (2003-2015) en Argentina es la modificacion en la normativa en matéria de migraciones, que constituye un avance significativo en la garantia de los derechos de la población inmigrante que habita en nuestro país. Tal como refiere Nicolao (2011), se desvanece la concepción comercialista en cuanto a integración regional, comenzando a emerger una concepción de impronta económica, política y social. Asumiéndose, en materia migratoria, un enfoque más aperturista, regionalista y con una fuerte impronta en materia de derechos humanos.

Fue a finales del año 2003 cuando se sancionó la Ley de Migraciones n. 25.871, que fue promulgada a inicios del año 2004 dejando si efecto la Ley Videla ${ }^{17}$ y enmarcando la Política Migratoria argentina hasta la actualidad. Esta mudanza fue posible a razón de la importante intervención de diversas Organizaciones de la Sociedad Civil (organismos de derechos humanos, iglesias, representantes sindicales, centros y grupos de investigación y otras organizaciones sociales), que influyeron tanto en la elaboración como en la reglamentación de la nueva Ley (Decreto n. 616, de 3 de mayo de 2010). Tambien debemos considerar aquí los tratados internacionales, en especial los realizados con los países de América Latina y el Caribe, bajo el paradigama de la Integracion regional. ${ }^{18}$

Podemos encontrar el núcleo fundamental de la Ley n. 25.871/2003 en su artículo 4, el cual refiere que

El derecho a la migración es esencial e inalienable de la persona y la República Argentina lo garantiza sobre la base de los principios de igualdad y universalidade. (ARGENTINA, 2003). 
Así, considera a los migrantes sujetos de derechos y se explicita el reconocimiento del derecho a migrar como un Derecho Humano, y la igualdad y universalidad como dos princípios a seguir. Asimismo, en los artículos 5, 6, 7 y 8 la normativa, refiere a la garantia de los derechos sociales de la población inmigrante, cuestión que nos interesa analizar en el próximo apartado.

4 AUH y PROGRESAR: programas inclusivos? Posibilidades y restricciones para el acceso de personas inmigrantes a los mismos

\subsection{Caracteristicas generales de los Programas}

En el mes de octubre del año 2009, el Poder Ejecutivo generó el Decreto de Necesidad y Urgencia (DNU) n. 1.602, de 29 de octubre de 2009, incorporándose al Sistema de Asignaciones familiares el Subsistema no contributivo de AUH para Protección Social. Este Programa, está dirigido a niños y niñas menores de dieciocho años, hijos e hijas de trabajadores desocupados o informales que perciben ingresos inferiores al salario mínimo vital y móvil. Contemplando también, a partir del año 2011, a mujeres embarazas (ARGENTINA, 2011).

La AUH se enmarca, tal lo expresado por el propio discurso oficial, en

[...] un nuevo paradigma de la Seguridad Social [...] en pos de resolver el problema de la desigualdad y el ejercicio efectivo de los derechos de la infancia. (ARGENTINA, 2013).

En este sentido, también encuentra fundamento en la Convención Internacional de los Derechos del Niño y en la Ley Nacional 26.061, de 18 de abril de 2006, que tiene como meta la Protección Integral de los Derechos de las Niñas, Niños y Adolescentes que habiten en el territorio nacional, reconociendo en su artículo 3 el interés superior del niño (SOTO; ESCURRA; DE AVILA, 2014).

El programa se centra en el grupo familiar de convivencia, designando responsabilidades al adulto a cargo, quien debe velar por el cumplimiento de las condicionalidades establecidas. ${ }^{19} \mathrm{En}$ cuanto al monto del ingreso transferido, cuando inició el Programa era de $\$ 180$ (pesos argentinos, equivalentes a US\$ $52,63)^{20}$ por cada hijo, incrementándose de manera escalonada, percibiendo las familias $\$ 837$ (pesos argentinos, equivalentes actualmente a US $\$ 88,10)^{21}$ por cada hijo desde el mes de junio del corriente año (CRISTINA..., 2015). Las famlias sólo reciben el $80 \%$ del total que debieran percibir mensualmente, produciéndose la entrega del $20 \%$ restante luego de verificado el cumplimiento de las condicionalidades. A partir del mes de abril del año 2015 los titulares de la AUH comenzaron a percibir la Ayuda Escolar Anual que ANSES abona habitualmente a los hijos de los trabajadores formales, extendiéndose así a los trabajadores no registrados. El monto es de $\$ 700$ (pesos argentinos, equivalentes a US $\$ 73,68)^{22}$.

A inícios del año 2014, cuando empieza a implementarse el PROGRESAR, que emerge como una continuidad de la $\mathrm{AUH}$, centrando sus esfuerzos principalmente en la educación para la posterior inserción laboral de los/as jóvenes "[...] reconociéndolos como titulares de derecho fundamental para el futuro de nuestro país." (ARGENTINA, 2014a). ${ }^{23}$ Este Programa se originó, también, como una medida de carácter excepcional, adoptada por el Poder ejecutivo nacional a través del Decreto n. 84, de 23 de enero de 2014. Está dirigido a jóvenes, pertenecientes a grupos sociales vulnerables, tal como es definido por el propio Programa, jovenes desocupados o que se desempeñan en la economía informal o formal, o son titulares de una prestación previsional contributiva, o pensión no contributiva, o monotributistas sociales, o trabajadores de temporada con reserva de puesto o del régimen de trabajadores de casas particulares. Esto, en la medida en que los ingresos monetarios propios o del grupo familiar no superen el monto de tres salarios mínimo vital y móvil (inicialmente era de sólo un salario mínimo, vital y móvil en el hogar, habiéndose extendido en el año 2015). ${ }^{24}$

El objetivo principal es

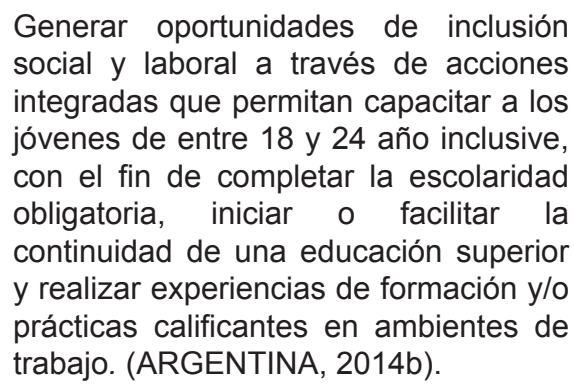

Para lo cual permite la Inscripción en todos los niveles educativos habilitados por la Ley de Educación Nacional ${ }^{25}$. La iniciativa buscaría, según se afirma, reducir la tasa de desempleo juvenil, que en Argentina alcanza en 2015 el 18,3\%. (Población total de entre 15 y 24 años de edad). Hombres: 15,3\%; Mujeres: 23,1\% (CENTRAL INTELLIGENCE AGENCY, [2015]).

En relación al monto y a la modalidad de pago de la prestación, el Programa estableció, en sus inicios, una suma de dinero, mensual de $\$ 600$ (pesos argentinos, equivalentes a US $\$ 81,08)^{26}$, que en el mes de marzo de 2015 ascendió a $\$ 900$ (pesos argentinos, equivalentes actualmente a US\$ 94,73 $)^{27}$, liquidándose el $80 \%$ del monto previsto. El $20 \%$ restante es abonado una vez que se acredita la asistencia a la entidad educativa, observandose el mismo mecanismo que en la AUH. En ambos Programas, el no cumplimiento de las condicionalidades implica la suspensión del pago, con posibilidades de ser excluidos del Programa. 


\subsection{Accesibilidad por parte de la población inmigrante a la AUH y al PROGRESAR}

Vimos que la población inmigrante, a razón de sus características socio-económicas se constituye en potencial usuaria tanto de la $\mathrm{AUH}$ como del PROGRESAR. Pero, ¿qué ocurre en la práctica? ¿Tienen acceso igualitario a los mismos, respecto a la población nativa, tal como lo establece la nueva Ley de Migraciones?

Como primera medida, cabe mencionar que en ninguno de los Documentos de los Programas analizados, se contempla explícitamente, el carácter de persona inmigrante. Luego, si observamos las condiciones para el ingreso y pemanencia establecidas por ambos, las mismas refieren al cumplimiento de los objetivos educativos y de controles sanitarios anuales, en consonancia con los PTCR de la Región, siendo éstas las condicionalidades más reconocidas y analizadas por los investigadores de ambos Programas. Al respecto, en el Documento Oficial del PROGRESAR se menciona como propósito de dichas condicionalidades

[...] mejorar las condiciones de vida y avanzar en la inclusión social de los grupos más vulnerables, permitiendo el desarrollo integral y sostenido de la persona. (ARGENTINA, 2014b).

En el caso de la AUH, el inciso e) de su Artículo 6, expresa que:

Hasta los CUATRO (4) años de edad -inclusive-, deberá acreditarse el cumplimiento de los controles sanitarios y del plan de vacunación obligatorio. Desde los CINCO (5) años de edad y hasta los DIECIOCHO (18) años, deberá acreditarse además la concurrencia de los menores obligatoriamente a establecimientos educativos públicos. (ARGENTINA, 1996).

Y, el PROGRESAR, en el inciso c) de su Artículo 3 , insta a

Acreditar la asistencia a una institución educativa de gestión estatal o a centros de formación acreditados ante el MINISTERIO DE TRABAJO, EMPLEO Y SEGURIDAD SOCIAL, al momento de la solicitud y su continuidad en los meses de marzo, julio y noviembre de cada año. (ARGENTINA, 2014b).

Respecto a la salud, requiere la inscripción en el Plan Sumar ${ }^{28}$ y los controles allí planteados.

Si nos remitimos a los articulos 7 y 8 de la Ley de Migraciones ${ }^{29}$ (ambos reglamentados) se apela allí a la garantia de los derechos concernentes a la salud y educación, que son, como vimos, condicionalidades requeridas en los PTRC, instando a las autoridades de los establecimientos educativos y entidades sanitárias a brindar atención y asesoramiento aún a aquellos inmigrantes que no han regularizado su situación al momento de arribar a las instituciones. ${ }^{30}$

Lo mencionado por estos artículos contituye un avance muy importante si recordamos la anteriror legislación, promovia práticas persecutórias y discriminatórias, alejando de este modo a los inmigrantes de los lugares de atención por temor a ser denunciados, restringiendose de este modo el acceso a los derechos mencionados. Encontramos, entonces, que no existirían obstáculos prestablecidos en cuanto al cumplimiento de la condicionalidades referidas a salud y educación.

Pero si analizamos en mayor profundidad los requisitos de ingreso, encontramos que ambos Programas consideran condición necesaria la tenencia de Documento Nacional de Identidad (DNI) argentino, tanto del niño/a, adolescente y joven, como de los responsables a cargo. En el caso de la $\mathrm{AUH}$ esto se explicita en el Artículo 6, inciso b): "Acreditar la identidad del titular del beneficio y del menor, mediante Documento Nacional de Identidad." $Y$ en el caso del PROGRESAR en su Artículo 3, Inciso a): "Acreditar identidad, mediante Documento Nacional de Identidad." (ARGENTINA, 1996).

Si bien el Artículo 30 de la Ley de Migraciones establece que "Podrán obtener el Documento Nacional de Identidad, los extranjeros con residencia permanente o temporária." (ARGENTINA, 2003). Puede observarse que los requisitos de los Programas implicarían un inconveniente para el acceso de la población inmigrante que aún no cuenta con este DNI, teniendo en cuenta las dificultades y demoras para realizar Iso trámites. En relación a esto, el Estado argentino generó en los años 2004 y 2005 un Plan Nacional de Normalización Documentaria Migratoria, iniciándose la regularización de ciudadanos de países que no pertenecen al MERCOSUR y, en una segunda etapa, conocida popularmente como Programa Patria Grande, se hizo extensivo a los inmigrantes procedentes de países del MERCOSUR. ${ }^{31}$ Pero, a pesar de facilitar el trámite se percibe que no alcanza a cubrir a la totalidad de la población objetivo. ${ }^{32}$

El mayor problema, sin embargo, parece residir en los requerimientos en cuanto a la antigüedad de residencia en Argentina por parte de quienes pretendan ingresar a los PTCR. Encontramos, en este aspecto, que la AUH establece en su Artículo 6, inciso a):

Que el menor sea argentino, hijo de argentino nativo o por opción, naturalizado o residente, con residencia legal en el país no inferior a TRES (3) 
años previos a la solicitud. (ARGENTINA, 2009b).

La Resolución n. 393, de 18 de noviembre de 2009 de la ANSES establece, asimismo, que tanto el titular y el beneficiario como el beneficiario deben poseer una residencia legal de 3 años, restringiéndose aún más el acceso (ARGENTINA, 2009a). En este caso, la condición irregular migratoria de los padres se estaría transmitiendo a la generación de sus hijos, en violación a tratados internacionales y las leyes migratorias y de infancia (CERIANI; CYMENT; MORALES, 2011). EI PROGRESAR, por su parte, exige "Ser argentino nativo o naturalizado o residente con una residencia legal en el país no inferior a CINCO (5) años previos a la solicitud." (ARGENTINA, 2014b, art. 3, inciso b), esto es, mayor cantidad de años, acentuándose la medida.

Si retomamos Ley de migraciones vigente en Argentina observamos que en sus artículos 5 y 6 se explicita que:

\begin{abstract}
Artículo 5: El Estado asegurará las condiciones que garanticen una efectiva igualdad de trato a fin de que los extranjeros puedan gozar de sus derechos y cumplir con sus obligaciones, siempre que satisfagan las condiciones establecidas para su ingreso y permanencia, de acuerdo a las leyes vigentes.

Artículo 6: El Estado en todas sus jurisdicciones, asegurará el acceso igualitario a los inmigrantes y sus familias en las mismas condiciones de protección, amparo y derechos de los que gozan los nacionales, en particular lo referido a servicios sociales, bienes públicos, salud, educación, justicia, trabajo, empleo y seguridad social. (ARGENTINA, 2003).
\end{abstract}

Si bien el primero no está reglamentado, en la reglamentación de Artículo 6 se deja constancia de que es el Ministerio del Interior, a través de la Dirección Nacional de Migraciones quien debe velar por el resguardo de los derechos humanos y el goce del derecho a migrar reconocido por la Ley, debiendo colaborar con otras áreas de los distintos niveles del Gobierno, para lograr la integración de los inmigrantes y garantizar ló establecido en los artículos mencionados. Como se percibe, estos artículos promueven asegurar el acceso igualitario de los inmigrantes, aún así no hay estrategia posible que pueda apresurar el ingreso de los mismos a los PTCR analizados, ya que resultan taxativos respecto a la antigüedad de residencia. Esto no sólo genera inconvenientes para la materialización de la Ley de Migraciones vigente. Vemos que tambien infringe, en primera instancia, el Artículo 20 de la Constitución Nacional Argentina, que refiere:
Los extranjeros gozan en el territorio de la Nación de todos los derechos civiles del ciudadano [...] Obtienen nacionalización residiendo dos años continuos en la Nación; pero la autoridad puede acortar este término a favor del que lo solicite, alegando y probando servicios a la República. (ARGENTINA, 1995).

Implica, también, tensiones respecto a los acuerdos internacionales, especialmente los establecidos entre los países de America Latina y el Caribe para la consolidación de su integración, en el marco de la cooperacion sur-sur (Mercado Comun del Sur (MERCOSUR $)^{33}$, Union de Naciones Suramericanas (UNASUR) ${ }^{34}$ y Comunidad de Estados Latinoamericanos y Caribeños (CELAC) ${ }^{35}$ ). En este sentido, recordemos que los incisos 22 Y 24 del artículo 75 de la Constitucion Nacional argentina, refieren a la adhesión a la normativa respecto a los Derechos Humanos, establecidos en el Derecho Internacional. Ceriani, Cyment y Morales (2011, p. 5) explican al respecto que:

El uso restringido de la ciudadanía atada a la nacionalidad o la residencia legal se apoya en la aplicación de una noción desfasada -contradictoria pero funcional- del principio de soberanía estatal en materia migratoria. Es decir, al regular las condiciones de ingreso a un país, también se fijan criterios diferenciadores para acceder a derechos fundamentales. [...] los Estados siguen intentando reafirmar su deteriorada soberanía con el objetivo de excluir a los - residuos de la globalización. (Bauman, 2005:78-81).

Encontramos, entonces, una gran contradicción al momento de evaluar el acceso de la población inmigrante a lo que fue reconocido como Derecho por estas normativas.

\section{CONCLUSIONES}

La AUH y el PROGRESAR constituyen actualmente dos pilares fundamentales del Sistema de Protección Social desplegado por Argentina en el marco del Modelo de Desarrollo con Inclusión desarrollado por el Gobierno Kirchnerista para afrontar los elevados índices de pobreza estructural y desigualdad que presenta nuestro país. ${ }^{36} \mathrm{Al}$ igual que la Politica Migratoria fueron planificados y son ejecutados bajo la bandera de los Derechos Humanos, la igualdad, la Inclusión Social, la Universalidad y la promoción del Desarrollo Humano, en el marco de acuerdos internacionales. 
Como se colocó en el desarrollo del trabajo, las condiciones para el acceso establecidas en los PTRC analizados limitan el proceso de materialización de los mismos, afectando en mayor medida a la población inmigrante que es una de las más vulnerables $\mathrm{y}$, por tanto, el Estado debiera adecuar sus intervenciones en pos de la garantía de sus derechos. La antigüedad en la residencia, es un criterio que claramente está imposibilitando que la totalidad de las personas inmigrantes que son potenciales usuarios puedan acceder al mismo. Entre ellos quedan inhabilitados, primeramente, quienes aún no han tramitado el Certificado de residencia, pero también los residentes temporarios ${ }^{37}$. Así es que existe un obstáculo importante para la materialización de esos derechos promulgados, tanto en las normativas mencionadas, como en la los propios Programas. Contradiciéndose, asimismo, los Tratados entre los países de la Region, quienes proclaman la integración para fines económicos, sociales, políticos y culturales que deriven en el bienestar de sus poblaciones. Como vemos, se está recurriendo a un uso restringido de la noción de ciudadanía (ASA; CERIANI CERNADAS, 2010) que, al ser asociada a la nacionalidad, lejos de contribuir a la universalidad, la inclusión y la igualdad, genera discriminaciones. Ser titulares de derechos no implica para los inmigrantes poder ejercerlos plenamente.

Por su parte, Eduardo Domenech (2007, p. 12) refiere que si bien

Estado ha adoptado el discurso pluralista o multiculturalista como parte constitutiva de su retórica de la inclusió [...], la formulación de las proposiciones acerca de la inserción de los migrantes denota la vigencia de la ideología asimilacionista.

Explica que

Mientras los discursos y políticas del
Estado se basan en la articulación de
los derechos humanos, la ciudadanía
comunitaria y el pluralismo cultural [...]
las prácticas estatales están dirigidas
fundamentalmente a la regularización
de la situación administrativa de los
migrantes [...] constituyéndose en el eje
transversal de las acciones emprendidas
recientemente. (DOMENECH, 2007, p. 7).

Pudimos visualizar esto al referirnos al Plan Nacional de Normalización Documentaria Migratoria establecido en Argentina en el año 2004.

Es importante mencionar también que, al analizar el PROGRESAR, se percibe que el Estado Nacional elabora programas de formación profesional para el empleo, con la intencionalidad discursiva de facilitar la creación de puestos de trabajo, la reinserción ocupacional, el empleo de los jóvenes y la transformación de las actividades informales, intentando incidir en la dinámica del Mercado de trabajo y en la configuración misma del mundo del trabajo. Pero excluye a gran cantidad de jóvenes inmigrantes que se encuentra empleado en los escalones más bajos del mercado de trabajo. Incluso, si nos basamos en la lógica de capital humano mencionada al inicio, contemplando que el principal objetivo del PROGRESAR es formar mano de obra para su inserción al mercado laboral, y que los ciudadanos de otros países arriban a Argentina mayormente en busca de trabajo ( $y$ si así no lo fuera, forma parte de las estrategias para reproducir su existencia), también se incurre en incoherencias al no permitir el acceso de los mismos al Programa, aún cuando, según se destaca desde la CEPAL (2014), en la coyuntura actual, quienes no adquieren las competencias necesarias para la sociedad del conocimiento tienen más probabilidades de sufrir marginación social y económica. Más allá de las críticas que puedan realizarse a la Teoría del Capital Humano, es necesario reconocer que son esas las reglas de juego instaladas, hasta tanto no generemos otras, superadoras. Cabe preguntarse, entonces, si en el marco de las acciones inclusivas en materias de políticas públicas, y de apelaciones a la integración de los inmigrantes a nuestro país y del respeto de sus derechos, promovidas por el Modelo vigente, esta omisión es producto de la ignorancia respeco a la importancia que tiene para tales fines el permitir el acceso de la población inmigrante a los PTRC; o debemos pensar que es parte de la estrategia que permite que la población inmigrante continúe siendo funcional al Sistema económico-productivo manteniendo sus condiciones de vulnerabilidad y precariedad.

En este sentido, es importante contemplar que

La elección tanto de las formas de intervención como de los contenidos de las políticas refiere al mantenimiento del proceso de hegemonía en una sociedad concreta, el cual se realiza no sin contradicciones. (SOTO, 2013, p. 55).

Es allí donde resulta necesario, y posible, generar estrategias que se constituyan en fuerzas tendientes a propiciar la garantía de los derechos conquistados, y la institución de nuevos, teniendo claridad respecto a la responsabilidad que le cabe al Estado en esta materia.

\section{REFERÊNCIAS}

ARGENTINA. Republica de la Nación. Administración Nacional de la Seguridad Social. Más de dos millones y medio de chicos que reciben 
la Asignación Universal comienzan a percibir también la Ayuda Escolar. Buenos Aires, 2015a. Disponible en:<http://anses.gob.ar/noticia/mls-dedos-millones-y-medio-de-chicos-que-reciben-laasignacion-universal-comienzan-a-percibir-tambienla-ayuda-escolar-219>. Acceso en: 4 oct. 2015.

Más de 790.000 jóvenes están estudiando con PROGRESAR. Buenos Aires, 2015b. Disponible en:<http://www.anses. gob.ar/noticia/mls-de-jovenes-estln-estudiando-conprogresar-288>. Acceso en: 1 sept. 2015.

Observatorio de la Seguridad Social Asignación Universal por hijo para Protección Social: Decreto 1.602/09. Boletin Cuatrimestral, Buenos Aires, jan./mar. 2013. Disponible en:<http://observatorio.anses.gob. ar/archivos/documentos/PPT\%20-\%20AUH\%20 I\%20C\%202013\%20F.pdf>. Acceso en: 1 oct. 2015.

\section{Programa de Respaldo} a Estudientes de Argentina - P.R.O.G.R.E.S.A.R. Buenos Aires, 2014a. Disponible en:<http://www. progresar.anses.gob.ar/institucional-1>. Acceso en:

Constitucion de la Nacion Argentina. Ley n. 24.430, de 3 de enero de 1995. Ordénase la publicación del texto oficial de la Constitución Nacional (sancionada en 1853 con las reformas de los años 1860, 1866, 1898, 1957 y 1994). Buenos Aires, 1995. Disponible en:<http://infoleg. mecon.gov.ar/infolegInternet/anexos/0-4999/804/ norma.htm>. Acceso en: 1 oct. 2015.

Ministerio de Economia y Finanzas Públicas. Administración Nacional de la Seguridad Social. Resolución 393, de 18 de noviembre de 2009. Asignación Universal por Hijo para Protección Social. Reglamentación. Buenos Aires, 2009a.

Decreto n. 1.602, de 29 de octubre de 2009. Incorpórase el Subsistema no Contributivo de Asignación Universal por hijo para Protección Social. Buenos Aires, 2009b. Disponible en:<http://www.infoleg.gov.ar/infoleglnternet/ anexos/155000-159999/159466/norma.htm>. Acceso en: 1 feb. 2014.

Decreto n. 616, de 3 mayo de 2010. Reglamentación de la Ley de Migraciones $\mathrm{N}^{\circ} 25.871$ y sus modificatorias. Buenos Aires, 2010.

Decreto 446, de 18 de abril de 2011. Modifícase la Ley $\mathrm{N}^{\circ} 24.714$ en relación con la Asignación por Embarazo para Protección Social. Buenos Aires, 2011.
Ley 24.714, de 16 de

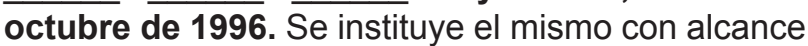
nacional y obligatorio. Derógase la Ley $\mathrm{N}^{\circ} 18.017$ y sus modificatorias, y los Decretos Nros. 770/96, $771 / 96,991 / 96$ y toda otra norma que se oponga al presente. Buenos Aires, 1996.

Ministério de Salud. El Programa

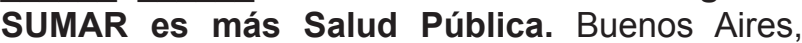
[2015a]. Disponible en:<http://www.msal.gob.ar/ sumar/index.php/institucional/programa-sumarmas-salud-publica>. Acceso em: 1 agosto 2015.

Seguros públicos de salud. Buenos Aires, [2015b]. Disponible en:<http:// www.msal.gov.ar/sumar/index.php/institucional/ seguros-publicos-de-salud>. Acceso en: 1 agosto. 2015.

Ministerio de Trabajo, Empleo y Seguridad Social. Decreto n. 84, de 23 de enero de 2014. Créase el "Programa de Respaldo a Estudiantes Argentinos" (PROG.R.ES.AR.). Buenos Aires, 2014b. Disponible en:<http://www.progresar. anses.gob.ar/institucional/resolucion-decreto-9>. Acceso en: 1 jul. 2015.

Programa Familias por la Inclusión Social. Buenos Aires, [2015c]. Disponible en:<http://www.trabajo.gov.ar/left/estadisticas/otia/ politicas/verPolitica.asp?id=39>. Acceso en: 1 sept. 2015.

Programa Jefes $\overline{\text { de Hogar. Buenos Aires, }}$ [2015d]. Disponible en:<http://www.trabajo.gov.ar/left/estadisticas/ otia/politicas/verPolitica.asp?id=38>. Acceso em: 1 marzo 2015.

Ministerio del Interior y Transportes. Dirección Nacional de Migraciones. DNI Extranjeros. Buenaos Aires, 2012. Disponible en:<http://www. migraciones.gov.ar/accesible/indexn.php?dni_ extranjeros>. Acceso en: 14 oct. 2015.

Ley n. 25.871,

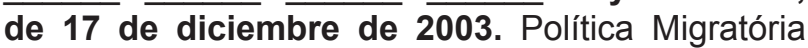
Argentina. Buenos Aires, 2003.

ASA, Pablo; CERIANI CERNADAS, Pablo. Migrantes, Derechos sociales y políticas públicas en América Latina y el Caribe: la universalidad en juego. In: ARCIDIÁCONO, Pilar; ESPEJO YAKSIC, Nicolás; RODRÍGUEZ GARAVITO, César (Coords.). Derechos Sociales: justicia, política y economía y América Latina. Bogotá: Siglo del Hombre Editores, 2010.

CARDONA, MArleny et al. Capital Humano: una mirada desde la educación y la experiencia laboral. Cuadernos de Investigación, Medellín, n. 56, p. 5-31, abr. 2007. 
CECCHINI, Simone; MADARIAGA, Aldo. Programas de Transferencias Condicionadas: balance de la experiencia reciente en América Latina y el Caribe. Santiago de Chile: CEPAL, 2011. (Cuadernos de la CEPAL, n. 95). Disponible en:<http://repositorio.cepal. org/handle/11362/27854>. Acceso em: 1 marzo 2015

CENTRAL INTELLIGENCE AGENCY. The Word Factbook: Country Comparison to the World. Washington, D.C.: [s. n.], [2015]. Disponible en:<https:// www.cia.gov/library/publications/the-world-factbook/ fields/2229.html>. Acceso en: 6 jul. 2015.

CERIANI, Pablo; CYMENT Carla; MORALES, Diego. Migración, derechos de la niñez y Asignación Universal por Hijo: las fronteras de la inclusión social. In: SEMINARIO INTERNACIONAL DE POLÍTICAS DE LA MEMORIA, 4., 2011, Buenos Aires. Anais eletrônicos... Buenos Aires: Centro Cultural de la Memoria Haroldo Conti, 2011. Disponible en:<ttp:// conti.derhuman.jus.gov.ar/2011/10/mesa_2/ceriani_ cyment_morales_mesa_2.pdf>. Acceso em: 1 marzo 2015.

CERRUTTI, Marcela. Diagnóstico de las poblaciones de inmigrantesen la Argentina. Buenos Aires: Ministerio del Interior/Secretaria de Interior/Dirección Nacional de Problación, 2009. (Serie de Documentos de la Dirección Nacional de Población, n. 2).

COMISIÓN ECONÓMICA PARA AMÉRICA LATINA Y EL CARIBE. Panorama Social de América Latina. Santiago de Chile, 2014.

CRISTINA Kirchner anunció el aumento del $30 \%$ de la Asignación Universal por Hijo y de las asignaciones por embarazo y familiares. La Nación, [S. I.], 2015. Disponible en:<http://www.lanacion.com. ar/1802056-cristina-kirchner-anuncio-el-aumentodel-30-de-la-asignacion-universal-por-hijo-y-de-lasasignaciones-por-embarazo-y-familiares>. Acceso en: 4 oct. 2015.

DOMENECH, Eduardo. La agenda política sobre migraciones en América del sur: el caso de la Argentina. Revue Européenne des Migrations Internationales, v. 23, n. 1, p. 1-19, 2007. Disponible en:<https://remi.revues.org/50>. Acceso em: 1 marzo 2015.

GÓMEZ, Abigail; PIANA, Ricardo. El migrante en Argentina y el acceso a sus derechos. Un breve recorrido por las normas, las políticas y sus historias. Revista Facultad de Derecho, Montevideo, n. 36, p. 101-126, ene./jun. 2014.

HARVEY, David. La condición postmoderna. Buenos Aires-Madrid: Amorroutu, 2004. 1ra. edición 1990.
INSTITUTO NACIONAL DE ESTADÍASTICAS Y CENSOS. Encuesta Permanente de Hogares (EPH). Buenos Aires, [2002]. Site http://www.indec. gov.ar/bases-de-datos.asp. Acceso em: 1 marzo 2015.

Censo Nacional de Población y Vivienda de 1970. Buenos Aires, 1970. Disponible en:<http:// www.santafe.gov.ar/archivos/estadisticas/censos/ Censo1970.pdf>. Acceso em: 1 marzo 2015.

\section{Censo Nacional de Población y Vivienda} de 1991. Buenos Aires, 1991. Disponible en:<http:// www.santafe.gov.ar/archivos/estadisticas/censos/ Censo1970.pdf>. Acceso em: 1 marzo 2015.

\section{Censo Nacional de Población y} Vivienda de 2001. Disponible en:<http:// www.indec.gov.ar/micro_sitios/webcenso/ censo2001s $2 /$ ampliada_index.asp? $\operatorname{mode}=01 \mathrm{P}$. Acceso em: 1 marzo 2015.

INSTITUTO SOCIAL DEL MERCOSUR. Línea de tempo. Asunción, [2011]. Disponible en: $<w w w$. mercosur.int>. Acceso en: 3 oct. 2015.

NICOLAO, Julieta. El Estado argentino ante el reto de las migraciones internacionales: reflexiones del reciente cambio de rumbo en la política migratoria argentina. Convergencia: Revista de Ciencias Sociales, México, n. 53, p. 205-228, mayo/agosto 2010.

Política migratoria argentina: el nuevo paradigma -. Los derechos humanos, el enfoque regional y la tradición aperturista. In: COLOMBO, Sandra (Comp.). La inserción internacional de Argentina durante la presidencia de Néstor Kirchner: un cambio de época. 1. ed. Tandil: CEIPIL, 2011. p. 109-140.

ORGANIZACIÓN INTERNACIONAL PARA LAS MIGRACIONES. Perfil Migratorio de Argentina 2012. Buenos Aires, 2012. Elaborado por Roberto Benencia.

PAULO NETTO, Jose. Cinco notas a propósito de la "cuestión social". Temporalis, Brasília, DF, n. 3, , p. 41-50, 2001. Disponible en:<http://pt.slideshare.net/ JooRafael1/revista-temporalis-3-2001>. Acceso en: 1 mar. 2015.

PERERA, Marcelo; VELAZQUEZ, Cecilia: Impacto del programa de regularizacion migratoria 'Patria Grande' en Argentina. Estudios Económicos, Bahia Blanca, v.30, n. 61, p. 43-69, jJu./dic. 2013.

SILVA, Maria Ozanira Silva de (Coord). Programas de transferência de renda na América Latina e Caribe. São Paulo: Cortez Editora, 2014. 
SOLIMANO, A. Globalización y migración internacional: la experiencia latinoamericana. Revista de la CEPAL, Santiago de Chile, n. 80, p. 55-72, agosto 2003.

SOTO, S. F. La política social y la recomposición material del consenso. La centralidad de los programas de transferencia de renta condicionada: el caso argentino. Serviço Social e Sociedade, São Paulo, n. 113, p. 53-85, jan./mar. 2013.

Políticas sociales, ciudadanía y espacio público. In: (Coord.). El Trabajo social y

la cuestión social: crisis, movimientos sociales y ciudadanía. Buenos Aires: Editorial Espacio, 2005.

ESCURRA, María; de AVILA, Verónica. La Asignación Universal por Hijo para protección social en Argentina: procesos de legitimación, derechos e infancia(s). Virajes y tensiones a inicios del siglo XXI. In: ENCUENTRO INTERNACIONAL DE EDUCACIÓN: espacios de investigación y divulgación, 1., 2014, Tandil. Anais... Tandil: NEES/ UNCPBA, 2014.

; TRIPIANA, J. El desarrollo del capitalismo y la nueva configuración de la protección social. La Asignación Universal por Hijo en Argentina. Textos e Contextos, Porto Alegre, v. 13, n. 2, p. $274-290$, jul./dic. 2014.

UNIÓN DE NACIONES SURAMERICANAS. ¿Quiénes Somos? Quito, [20--?]. Disponible en:<www.unasursg.org>. Acceso en: 3 oct. 2015.

YAZBEK, Maria Carmelita. Pobreza e exclusão social: expressões da Questão Social no Brasil. Temporalis, Brasília, DF, n. 3, p. 33-40, 2001. Disponible en:<http://pt.slideshare.net/JooRafael1/ revista-temporalis-3-2001>. Acceso en: 1 sept. 2015.

\section{NOTAS}

1 Referenciándonos en la Teoría crítica se entiende aquí al Estado como: "[...] totalidad compleja que articula a través de prácticas y concepciones teóricas no sólo el dominio de la clase dirigente sino también el consenso activo. De esta manera el fenómeno estatal no constituye una cosa burocrática neutra, sino un proceso de relaciones sociales que si bien se cristalizan en aparatos burocráticos, es dinámico en tanto la construcción y mantenimiento de la dirección supone no sólo dominio sino también legitimación, consenso, permitiendo la realización de la hegemonía." (SOTO, 2013, p.55)

2 Paulo Netto (2001, p. 41, grifos do autor) explica que esta expresión surge en la década de 1930, “[...] para dar conta do fenômeno mais evidente da história da Europa Ocidental que experimentaba os impactos da primeira onda industrializante, iniciada na Inglaterra no último quartel do século XVIII: trata-se do fenômeno do pauperismo. Com efeito, a pauperização (neste caso absoluta) massiva da população trabalhadora constituiu o aspecto mais imediato da instauração do capitalismo em seu estágio industrial -concorrencial [...] Em efeito, se não era inédita a desigualdade entre as várias camadas sociais, se vinha de muito longe a polarizacão entre ricos e pobres, se era antiqüíssima a diferente apropiação e fruição dos bens sociais, era radicalmente nova a dinâmica da pobreza que então se generalizava. Pela primeira vez na história registrada, a pobreza crescia na ração direta em que aumentava a capacidade social de produzir riquezas."

3 Al respecto resulta interesante colocar una reflexión de Yazbek (2001, p. 35), quien expone: "É bom lembrar ainda, que a pobreza é uma face do descarte de mão de obra barata, que faz parte da expansão capitalista. Expansão que cria uma população sobrante, gente que se tornou não empregável, parcelas crescentes de trabalhadores que não encontram um lugar reconhecido na sociedade, que transitam à margem do trabalho e das formas de troca socialmente reconhecidas (Telles, 1998). Expansão que cria o necessitado, o desamparado e a tensão permanente da instabilidade no trabalho. Implica a disseminação do desemprego de longa duração, do trabalho precário, instável e intermitente, dos biscates e de outras modalidades de relacionamento da força de trabalho com o capital, que em sua essência representam una mesma ordenação da vida social."

4 Se denomina asía las diez orientaciones que organismos internacionales, entre los que se destacaron el FMI y el BID, realizaron hacia los países entonces denominados subdesarrollados o en vías de desarrollo con la finalidad de contribuir a superar las crisis económicas por las cuales atravesaban.

5 "El centro de la teoría del Capital Humano está en tomar la educación y capacitación como formas de inversión que producen beneficios a futuro con mayores ingresos para las personas con educación, y por ende, para la sociedad en su conjunto. Según Schultz (1961), invertir en escolarización, salud, en la forma de crianza de los niños, en profesionales, en investigación, es invertir en capital humano, lo que a su vez disminuye la brecha entre pobres y ricos, brindándoles una mejor calidad de vida a las personas de escasos recursos.; Becker (1964) define el capital humano como el conjunto de las capacidades productivas que un individuo adquiere por acumulación de conocimientos generales o específicos. El individuo incurre en gastos de educación al mismo tiempo que en un costo de oportunidad por permanecer en la población económicamente inactiva y no recibir renta actual; sin embargo, en el futuro su formación le otorgará la posibilidad de obtener unos salarios más elevados." (CARDONA et al., 2007, p.18-20).

$6 \quad$ Según la base de datos de programas de protección social no contributiva en América Latina y el Caribe, de la Comisión Económica para América Latina (CEPAL), en el año 2011 los PTRC ya operaban en 18 países de la Región, alcanzando a más de 25 millones de familias (alrededor de 113 millones de personas), 
es decir, el $19 \%$ de la población de América Latina y el Caribe, a un costo que rondaba el $0,4 \%$ del PIB regional, lo cual nos alerta sobre la gran magnitud adquirida (CECCHINI; MADARIAGA, 2011).

7 Al respecto, Silva (2014) señala que, los nuevos enfoques de protección social en America Latina, denotan una perspectiva monetarista de la pobreza, razón por la cual puede entenderse que recurran centralmente a la transferencia de renta como mecanismo para superar, a corto plazo, la pobreza intergeneracional.

8 La década de 1990, bajo la presidencia de Carlos Saúl Menem, se destacó, como en otros países latinoamericanos, por el despliegue de las políticas neoliberales, desarrolladas en base a lineamientos del Consenso de Washington, con la prevalencia de políticas socio- asistenciales signadas por la hiperfocalización, la segmentación y la fragmentación. El Estado nacional generó descentralizaciones a los niveles provincial y municipal. Asimismo, las Organizaciones de la Sociedad Civil comienzan a tomar preponderancia, en cuanto asumen gran parte de la responsabilidad estatal en diversos ámbitos, ante la retracción del mismo en torno a la política asistencial. Las privatizaciones fueron una de las principales estrategias económicas gubernamentales y se generó un enorme endeudamiento externo. La economía creció, sin embargo, esto no se vio traducido en reducción de la pobreza y de las desigualdades sociales tal lo prometido, sino que, de forma contraria, se vieron acentuadas, registrándose un aumento significativo de la pobreza y la indigencia.

9 Nuevamente, la Sociedad Civil, esta vez liderada por la denominada clase media, tomó protagonismo con novedosasmovilizaciones en reclamo de sus derechos derivando esto, en el aspecto político- institucional, en la renuncia de Fernando de la Rúa a su mandato presidencial, con la posterior sucesión de cinco presidentes en solo 15 días. Fue la consecuencia de la problemática económica que atravezaba el país, caracterizada por una una marcada recesión, con fuga de capitales, endeudamiento acelerado, agotamiento de las fuentes de financiación, etc., lo que derivó en altas tasas de desempleo y pobreza.

10 Destinado a "Jefes/as de hogar con hijos de hasta dieciocho años de edad, o discapacitados de cualquier edad, y a hogares en los que la jefa de hogar o la conyugue, concubina o cohabitante del jefe de hogar se hallare en estado de gravidez, todos ellos desocupados y que residan en forma permanente en el país [...] Los beneficiarios del Programa Jefes de Hogar percibian una ayuda económica no remunerativa de $\$ 150$.- mensuales, a cambio de la cual debian realizar alguna tarea o acción a la que se denominaba contraprestación." (ARGENTINA, [2015d]). El Programa se financió con fondos del Tesoro Nacional y el préstamo BIRF 7369 AR.

11 El Programa Familias es una reformulación del Programa Ingreso para el Desarrollo Humano (IDH) creado en 2003. Incluyó inicialmente a beneficiarios del PJJD que cumplieran con las condiciones de elegibilidad y permanencia del Plan y a los beneficiarios del IDH. Entre sus componentes figuran los ingresos no remunerativos, para familias con hijos o menores de 19 años de edad a cargo, que se encuentren por debajo de la línea de pobreza. El monto del subsidio va de los $\$ 155$ a los $\$ 305$, dependiendo de la cantidad de niñas/os a cargo. EL organismo ejecutor es el Ministerio de Desarrollo Social, y el financiamiento proviene del Tesoro Nacional y de aportes del BID (ARGENTINA, [2015c].

12 Con relación al impacto de las $\mathrm{AUH}$, de acuerdo a lo señalado en el portal de Noticias de la ANSES, para abril de 2015, 3.621.129 niños, niñas y adolescentes (aproximadamente el $38 \%$ del total) percibían la AUH, siendo 2.012.225 familias las alcanzadas por el Programa (ARGENTINA, 2015a). Respecto AL PROGRESAR, se estima que al comienzo del programa, en febrero de 2014, la cantidad de inscriptos a era de 217.766. Y en junio de 2015 llegó a 790.114 , lo que implicaría un aumento del $262,83 \%$ (ARGENTINA, 2015b).

13 Se denomina así, en en Argentina, al período de mandatos presidenciales ejercidos por Néstor Kirchner en un inicio (período 2003-2007) y continuado por su esposa Cristina Fernández de Kirchner (período 2007-2015).

14 Junto con Estados Unidos y Brasil la Argentina fue uno de los países receptores más significativos de la inmigración transatlántica de finales del siglo XIX y comienzos del XX (CERRUTI, 2009). En este sentido, en el año 1914 se genera un pico de afluencia de ciudadanos europeos a nuestro país, producto de las guerras y la política migratoria receptiva desarrollada en ese momento histórico.

16 En este aspecto es importante tener en cuenta lo establecido en los artículos 14, 14 bis y 16 de la Constitucion Nacional Argentina y a los Articulos 16 y 52 de la Ley de Migraciones, que refieren a los derechos laborales, que no estarian garantizándose a estos trabajadores. Por razones de espacio no se abordaran en el presente artículo.

17 A mediados de la década de 1970, en el marco de la última Dictadura Militar, el Estado nacional, en consonancia con las expresiones a nivel internacional, desarrolló políticas migratorias expulsivas y persecutorias, que se iniciaron con la promulgación de la llamada Ley Videla (Ley núm. 23.439, de 27 de marzo de 1981), basada en la Doctrina de Seguridad Nacional. La misma fue aplicada por la la Dirección Nacional de Migraciones (DNM), que sostuvo un comportamiento excesivamente burocrático en la gestión de los trámites de regularización, y prácticas discriminatorias hacia los extranjeros procedentes de la región latinoamericana en el otorgamiento de las radicaciones. Se promovían prácticas persecutorias para aquellos inmigrantes que no habían regularizado su situación, llegando incluso a realizarse detenciones sin las órdenes correspondientes y allanamientos ilegales a los hogares de los mismos, vulnerando aún más los Derechos de esta población (NICOLAO, 2010).

18 Entre los considerandos de la reglamentacion de la Ley n. 25.871 (Decreto n. 616/2010), se menciona 
que: "[...] resulta necesario tener presente que la REPUBLICA ARGENTINA ha reformulado los objetivos de su política migratoria, en un marco de integración regional latinoamericana y de respeto a los derechos humanos y movilidad de los migrantes, lo que genera un compromiso cada vez mayor de cooperación mutua entre los diversos Estados Parte del MERCADO COMUN DEL SUR (MERCOSUR) y sus Estados Asociados, una progresiva facilitación de los procedimientos legales vigentes y una adecuada contemplación de las necesidades reales de los extranjeros que transitan o residen en el Territorio Nacional [...]". (ARGENTINA, 2010).

19 Así, la familia aparece ubicada en una dimensión instrumental al servicio del Estado, para ayudarle en el gobierno de los individuos, con lo cual el Estado queda autorizado para intervenir en la vida privada de la familia y exigirle una rendición de cuentasde lo actuado (SOTO; ESCURRA; DE AVILA, 2014).

20 Valor estimado a partir de la cotización del dólar en el mes de enero de 2009, en Argentina.

21 Valor estimado en relación a la cotización del dólar el día 9 de octubre de 2015 en Argentina. Cabe mencionar que en el mes de junio, cuando se produjo la modificación del valor de la transferência, el monto en dólares era mayor $(\$ 92,18)$ la moneda argentina continuó devaluándose, sin haberse modificarse, ante esto, el monto neto en pesos argentinos de la transferencia.

22 Valor estimado en relación a la cotización del dólar el día 9 de octubre de 2015 en Argentina.

23 Un antecedente importante lo constituye el Programa Jóvenes con más y mejor Trabajo, que según se evalúa desde la propia Política nacional, generó oportunidades de inclusión social y laboral a miles de jóvenes permitiendo finalizar su escolaridad obligatoria, realizar experiencias de formación y/o prácticas calificantes en ambientes de trabajo y finalmente insertarse en un empleo o iniciar una actividad productiva de manera independiente (ARGENTINA, 2014a).

24 El artículo 8 aclara que "El grupo familiar del solicitante está constituido por los padres o tutores salvo que el joven haya contraído matrimonio o se encuentre conviviendo en pareja en cuyo caso se considerará al cónyuge o conviviente." (ARGENTINA, 2014). Y en el Artículo 9, se contempla a jóvenes que no cuentan con grupo familiar, previendo la evaluación individual de la situación del mismo.

25 La Ley de Educación Nacional n. 26.206, 14 de diciembre de 2006, contempla: Niveles, primario, secundario, terciario, universitario, centros habilitados para el Plan FinEs del Ministerio de Educación, Bachilleratos Populares y Centros de Formación Profesional registrados ante el Ministerio de Educación o el Ministerio de Trabajo Empleo y Seguridad Social. Contempla, asimismo, la posibilidad de realizar un curso de Orientación e Inducción al Mundo del Trabajo pensado desde el Ministerio de Trabajo especialmente para Jóvenes. En el mismo se abordan las siguientes temáticas: derechos laborales; Técnicas para buscar trabajo; Intereses y habilidades para conseguir un trabajo; Seguridad e higiene en el trabajo; Uso de medios informáticos en el ámbito laboral (Disponible en:<https://docs.google. com/document/d/1J154oiL96qK-Z-h9lkmuP4uxx4TR3sHly8CdCluFA8/edit>).

26 Valor estimado en relación a la cotización del dólar el día 23 de enero de 2015, fecha del Decreto del Programa.

27 Valor estimado contemplando la cotiación del dólar el día 9 de octubre de 2015. Cabe mencionar que en el mes de marzo de 2015 el monto en dólares era de US\$101,69, visualizandose ahora una notable reducción debido a la sistemática devaluación de la moneda argentina.

28 "Este Programa se configura como un esquema de aseguramiento público de la salud que asocia y vincula derechos con prestaciones y servicios." (ARGENTINA, [2015b]). Se conformó como una continuidad del Plan Nacer, originado y puesto en funcionamiento en el año 2004 con el fin de brindar cobertura de salud a las embarazadas y niños de 0 a 5 años de edad. EI SUMAR, se desarrolló como una ampliación de políticas sanitarias con la pretensión, en sus inicios, de asegurar la atención y el cuidado a la salud a mujeres embarazadas, niños/ as, adolescentes y mujeres hasta 64 años de edad y varones hasta los 17 años. A partir de la creación del PROGRESAR, se incorporó a los varones hasta los 24 años de edad. Y, recientemente, el Programa se amplió a hombres hasta los 64 años de edad (ARGENTINA, [2015a]).

29 "Artículo 7: En ningún caso la irregularidad migratoria de un extranjero impedirá su admisión como alumno en un establecimiento educativo, ya sea este público o privado; nacional, provincial o municipal; primario, secundario, terciario o universitario. Las autoridades de los establecimientos educativos deberán brindar orientación y asesoramiento respecto de los trámites correspondientes a los efectos de subsanar la irregularidad migratoria. Artículo 8: No podrá negársele o restringírsele en ningún caso, el acceso al derecho a la salud, la asistencia social o atención sanitaria a todos los extranjeros que lo requieran, cualquiera sea su situación migratoria. Las autoridades de los establecimientos sanitarios deberán brindar orientación y respecto de los trámites correspondientes a los efectos de subsanar la irregularidad migratória." (ARGENTINA, 2003).

30 En este sentido, mantiene coherencia con la Ley de Educación Nacional n. 26.206/2006, que proclama proveer una educación integral, permanente y de calidad para todos/as los/as habitantes de la Nación, garantizando la igualdad, gratuidad y equidad en el ejercicio de este derecho. Si contemplamos que una cantidad considerable de inmigrantes no tienen la posibilidad de educarse en sus países de origen, al no contar con un sistema educativo gratuito, es un avance significativo. En cuanto al acceso a salud, la población inmigrante puede recibir las prestaciones gratuitas que proveen los diversos programas, 
entre ellos el REMEDIAR que brinda cobertura farmacológica directa a los usuarios y el Programa NACER/SUMAR.

31 Así es como en los años 2006 y 2008, iniciando el trámite con este último programa cerca del $30 \%$ de los extranjeros que residían en el nuestro país (PERERA; VELÁZQUEZ, 2013).

32 El Gobierno argentino ha desplegado, asimismo, otras estrategias tendientes a facilitar la regularización, utlizando como mediación programas e instituciones a las cuales acude la población inmigrante, tales como establecimientos educativos y de salud, capacitando incluso a los agentes de las mismas, tal lo dispuesto en la ley de Migraciones, a fin de captarlos y colaborar en la regulación de su situación de residencia en el país. Y ha acelerado los trámites correspondientes. Bajo el slogan: Por el Derecho a ser quien cada uno es. Por el derecho a todos los derechos, en la página web de Migraciones se informa que en todos los Registros Civiles del país puede tramitarse el nuevo Documento Nacional de Identidad (formato tarjeta) para todos los ciudadanos argentinos y para aquellos residentes extranjeros cuya situación migratoria los habilite, obteniéndolo por medio de dos modalidades: "Ventanilla única: esta opción posibilita al extranjero solicitar el DNI en forma conjunta con el trámite de residencia [...] Tradicional: [...] para aquellos extranjeros que ya cuentan con residencia permanente o temporaria vigente en el país." (ARGENTINA, 2012).

33 EI MERCOSUR, está integrado por Argentina, Brasil, Paraguay, Uruguay, Venezuela, con Bolivia, Chile, Colombia, Ecuador y Perú como miembros asociados. Su cración tuvo como objetivo principal "[...] propiciar un espacio comun que generara oportunidades comerciales y de inversiones a través de la integracion competitiva de las economias nacionales al mercado internacional." (INSTITUTO SOCIAL DEL MERCOSUR, 2011).

34 La UNASUR (20--?) es el mayor bloque economico de la Region. Fue creada en el año 2008 con el objetivo de "[...] construir un espacio de integración en lo cultural, economico, social y politico, respetando la realidad de cada nación. Nuestro desafio es eliminar la desigualdad socioeconomica, alcanzar la inclusion social, aumentar la participacion ciudadana, fortalecer la democracia y reducir las asimetrías existentes, considerando la soberanía e independencia de los Estados."

35 La CELAC, creada en el mes de febrero del año 2010, agrupa a los 33 países de America Latina y el Caribe. Tiene la visión de profindizar el crecimiento inclusivo y entre sus valores se destaca el respeto por los derechos humanos. Se propone trabajar sobre la base de la solidaridad; la inclusión social; la equidad e igualdad de oportunidades; la complementariedad; flexibilidad; la participación voluntaria; pluralidad y diversidad. Para mayor información remitirse a:<http:// cooperacionarg.gob.ar/es/celac>

36 Si observamos los datos producidos por el INDEC, a partir del año 2003 se produce una notable disminución de los índices de pobreza e indigencia; y una reducción de la desocupación que pasa de $21,5 \%$ (2002) al $7,2 \%$ en 2012. Aún así, actualmente el
$34,4 \%$ de los trabajadores se encuentra precarizado y la desigualdad continúa siendo una característica sobresaliente en nuestra sociedad, subsistiendo un patrón regresivo de distribución del ingreso (SOTO; TRIPIANA, 2014).

37 Donde están incluidos, según consta en el en el artículo 23 de la Ley de Migraciones, "a) Trabajador migrante: quien ingrese al país para dedicarse al ejercicio de alguna actividad lícita, remunerada, con autorización para permanecer en el país por un máximo de tres (3) años, prorrogables, con entradas y salidas múltiples, con permiso para trabajar bajo relación de dependencia; [...] j) Estudiantes: quienes ingresen al país para cursar estudios secundarios, terciarios, universitarios o especializados reconocidos, como alumnos regulares en establecimientos educativos públicos o privados reconocidos oficialmente, con autorización para permanecer en el país por dos (2) años, prorrogables, con entradas y salidas múltiples [...] k) Asilados y refugiados [...] por el término de dos (2) años, prorrogables [...]I) Nacionalidad: Ciudadanos nativos de Estados Parte del MERCOSUR, Chile y Bolivia, con autorización para permanecer en el país por dos (2) años, prorrogables con entradas y salidas múltiples [...]" (ARGENTINA, 2003).

\section{Verónica de Avila}

Assistente social

Mestranda em Ciencias Sociales pela Universidad Nacional del Centro de la Provincia de Buenos Aires (UNICEN), com período sanduiche no Programa de Pós-Graduação em Políticas Públicas (PPGPP) da Universidade Federal do Maranhão (UFMA)

E-mail: verodeavila@hotmail.com

\section{Universidad Nacional del Centro de la Provincia de Buenos Aires - UNICEN}

Gral. Pinto 399, B7000GHG Tandil, Buenos Aires, Argentina

Universidade Federal do Maranhão - UFMA

Av. dos Portugueses, 1966 - Bacanga, São Luís/MA

CEP: $65080-805$ 